\title{
A abordagem histórica do letramento: ecos da memória na atualidade
}

\author{
Leda Verdiani Tfouni* \\ Dionéia Motta Monte-Serrat** \\ Diana Junkes Bueno Martha***
}

\begin{abstract}
Resumo
A palavra letramento adquiriu uma polissemia que a afasta da noção de processo sócioistórico e a associa à codificação-decodificação da escrita. Sob essa concepção, não teríamos nada a acrescentar. Defendemos neste artigo, sob o enfoque da análise do discurso pêcheutiana e da psicanálise lacaniana, a concepção de letramento como fenômeno que influencia indiretamente culturas e indivíduos que não dominam a escrita, por ser um processo mais amplo do que a alfabetização. Como evidência dessa proposta, analisamos o texto de um aluno, que, instado a escrever sobre um tema distante da realidade em que vive, mobiliza lugares do arquivo e de sua memória particular, indicando um conhecimento da cultura escrita, mesmo que seu produto mostre a interpenetração de formas orais e escritas da língua, fato este que não é aceito por aqueles que defendem uma concepção a-histórica de letramento. Discutimos que sua escrita escapa das malhas redutoras de uma ideologia pedagogizante e reflete coerência discursiva estrutural ao desafio que lhe foi colocado. Propomos, ao final, que os educadores, em suas práticas, favoreçam a emergência da autoria de seus alunos.
\end{abstract}

Palavras-chave: Letramento. Análise do discurso. Ideologia.

*Professora Titular Sênior da Faculdade de Filosofia, Ciências e Letras de Ribeirão Preto, Universidade de São Paulo, (FFCLRP-USP), com estágio de pós-doutorado na Sorbonne III e na Universitá di

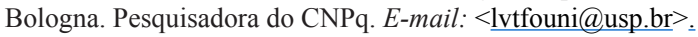

**Doutora em Psicologia pela Faculdade de Filosofia, Ciências e Letras de Ribeirão Preto, Universidade de São Paulo. Bolsista CAPES-BEX 4394/10-0, com estágio-sanduíche na Universidade SorbonneNouvelle, Paris 3 (set./dez. 2010), sob coorientação do Prof. Jean-Jacques Courtine. Bolsista da Fapesp 09/54417-4 e estágio na École des Hautes Études en Sciences Sociales (fev. 2012), sob orientação do Prof. Marcello Carastro.E-mail: <di_motta61@yahoo.com.br>.

***Doutora em Estudos Literários pela Universidade Estadual Paulista Júlio de Mesquita Filho (Unesp, Araraquara). Pós-doutora em Análise do Discurso pela Universidade de São Paulo. Professora visitante da Universidade de Yale (2012) e da Universidade de Illinois (2010). Professora de Literatura Brasileira Unesp/Ibilce, São José do Rio Preto, onde coordena o Grupo de Estudos de Poesia e Cultura (GEPOC/CNPq). Para citações, ver também: Diana Junkes Bueno Martha-Toneto.E-mail: < dijunkes@ gmail.com>. 


\section{Introdução}

A necessidade de se começar a falar em letramento surgiu da tomada de consciência, principalmente entre os linguistas, de que havia alguma coisa além da alfabetização, que era mais ampla, e até determinante desta. No entanto, no processo de atribuição do novo sentido da palavra letramento, em função das várias posições teóricas adotadas, pode-se dizer que, no estado atual, já existe uma polissemia relacionada à mesma, o que torna a sua conceituação complicada e confusa.

Diante disso, sentimos a necessidade de explicitar aqui nossa posição de que letramento é, para nós, um processo, cuja natureza é socioistórica. Pretendemos, com essa colocação, tecer considerações sobre o que é a escola para todos. No entanto, antes de nos aprofundarmos nesse assunto, iremos discorrer sobre as outras concepções de letramento atualmente em uso, e às quais nos opomos, por não serem nem processuais nem históricas, ou então por adotarem uma posição, a nosso ver, enfraquecida ou menos rigorosa quanto à sua opção processual e histórica. Referimo-nos a trabalhos em que a palavra letramento é associada a uma ideologia pedagógica prescritivista, usada como sinônimo de alfabetização, ou de técnicas relacionadas à escrita e seus usos, principalmente na escola".

$\mathrm{Na}$ bibliografia em língua inglesa, que, aliás, é citada descuidadamente por alguns, tem-se, sob o rótulo literacy, uma variedade de definições e visões. Aí está, cremos, uma das origens de mal-entendidos entre os que trabalham na área, e que acabam usando indiferenciadamente letramento como equivalente vernáculo de qualquer das acepções englobadas pelo vocábulo inglês.

Apenas a título de ilustração, apresentaremos a seguir, com base no que apontou Tfouni (1988, 1992, 2006b), algumas das perspectivas sob as quais o termo literacy tem sido focalizado na literatura de língua inglesa, principalmente norte-americana:

1- Em uma primeira perspectiva, que denominamos individualista-restritiva, o termo literacy é visto como voltado unicamente para a aquisição da leitura/escrita, considerando-se aí, portanto, a aquisição da 
escrita enquanto código, do ponto de vista do indivíduo que aprende. Desse conceito decorre uma relação por extensão entre literacy e escolarização, ensino formal, e aprendizado de habilidades específicas (como: aprender o alfabeto, correspondência som/grafema, pré-requisitos psicomotores). Sob essa perspectiva, então, literacy confunde-se com alfabetização. Exemplos desse uso do termo são:

[Literacy é] habilidade para ler e escrever, relacionada com a escolarização e seu sucesso. (LANGER, 1987, p. 2). Um constructo unitário, que chega a um final descritível e controlável pela aquisição de habilidades específicas (idem).

2- Sob uma segunda perspectiva, que pode ser chamada tecnológica, o termo literacy está relacionado ao conceito de produto, com seus usos em contextos altamente sofisticados. Assim conceituado literacy abrange uma visão positiva dos usos da leitura/escrita, relacionando-os com o progresso da civilização e o desenvolvimento tecnológico, o que pode ser ilustrado com as seguintes citações:

Literacy é a habilidade para entender materiais escritos, para a qual é importante a informação partilhada, e está relacionada com as necessidades da informação industrial (JACOB, 1984, p. 73).

[...] é essencial para o discurso científico e a organização da indústria, governo e educação. [...] É também usada extensivamente no comércio em geral em sua relação com o público (ANDERSON; STOKES, 1984, p. 24).

3- Existe ainda uma terceira perspectiva, a cognitivista, que enfatiza o aprendizado como produto das atividades mentais e, consequentemente, vê o indivíduo (criança) como responsável central pelo processo de aquisição da escrita, uma vez que pressupõe que o conhecimento e as habilidades têm origem nesse indivíduo. Tem como foco, portanto, os processos internos, e ignora as origens sociais e culturais do letramento. Exemplos dessa posição na literatura são os seguintes: 
Esta abordagem tenta explicar o que uma criança individual está fazendo e aprendendo. Focaliza as habilidades, o conhecimento e as intenções de crianças individualmente; (focaliza) aquilo que é "aprendido" (OLSON, 1984, p. 185 - destaque do autor).

É o conjunto de informações que todos os leitores competentes possuem. É a informação de fundo, armazenada em suas mentes, que permite que eles leiam um jornal com um nível adequado de compreensão, entendendo o assunto (HIRSCH, 1987, p. 2).

Colocadas em evidência, essas três posições deixam à mostra, para o leitor, que têm um ponto em comum: a concepção de literacy enquanto aquisição da leitura/ escrita. Com efeito, não importa a perspectiva tomada como ponto de partida: a ênfase é sempre colocada nas práticas, habilidades, no conhecimento, voltados sempre para a codificação/decodificação de textos escritos. Ou seja, existe aí uma superposição entre letramento e alfabetização. Em segundo plano, às vezes de maneira apenas sugerida, aparece também uma relação entre letramento, escolarização e ensino formal.

Práticas letradas, no contexto aí delineado, seriam sempre práticas de leitura/ escrita de textos. Além disso, percebe-se uma preocupação em focalizar produtos, quer no plano individual (perspectivas individualista e cognitivista), quer no social (perspectiva tecnológica). Letradas seriam, então, somente, aquelas pessoas que sabem ler e escrever, ou seja, pessoas alfabetizadas e escolarizadas. Inversamente, iletrado poderia ser usado como sinônimo de analfabeto. As perspectivas acima delineadas configuram uma ideologia cujo efeito consiste em separar formas de pensamento, ou raciocínio superiores de outras, inferiores (sem escrita). A mesma separação radical, denominada por Street (1989) de “a grande divisa”, é utilizada para comparar culturas com e sem escrita.

Encontramos ecos dessas posições, que denominamos a-históricas, no discurso de professores que, convidados a definir letramento, afirmam o seguinte:

Aluno letrado para mim é "aluno culto", é um aluno que sabe um pouco de tudo, que tem muitas informações.

"Criança letrada" é criança viva, esperta, que sabe ler e escrever corretamente e portanto é "plenamente alfabetizada"; quero dizer, aproveitou ao máximo tudo o que a escola tinha para lhe oferece.

"Letrado é o aluno que frequenta a escola", que "sabe ler, falar e escrever e redigir um texto corretamente". 
Para mim, o aluno trocar "f" por "v" é "um erro muito grave". Como é que eu posso aprovar uma criança que ainda é "analfabeta"? (ASSOLINI, 2003 - destaques do autor).

Alguns autores, que "embarcaram na moda do letramento", filiam-se a esse discurso que, a nosso ver, é discriminatório porque coloca em posição de inferioridade aqueles que não sabem ler nem escrever. É o caso de Magda Soares, para quem

letramento é o exercício efetivo e competente da tecnologia da escrita, que implica habilidades várias como: capacidade de ler ou escrever para atingir diferentes objetivos habilidades de orientarse pelos protocolos de leitura que marcam o texto, ao escrever; atitudes de inserção efetiva no mundo da escrita, tendo interesse e prazer em ler e escrever, sabendo utilizar a escrita para encontrar ou fornecer informação e conhecimento, escrevendo e lendo de forma diferenciada, segundo as circunstâncias, os objetivos, o interlocutor (SOARES, 2003, p. 92).

Chamamos a atenção para alguns significantes da citação acima: "tecnologia da escrita", "habilidades", "protocolos", "inserção efetiva", "sabendo utilizar a escrita". Retornando às três perspectivas a-históricas apresentadas acima, pode-se identificar que todas elas estão presentes no recorte retirado de Soares. Parece que a autora está aprisionada por um significado dicionarizado de "letrado": pessoa culta, de muito conhecimento, sobretudo livresco. O preocupante dessa postura é que a exclusão das crianças pobres que não são alfabetizadas adequadamente, bem como de todos os analfabetos, adquire aqui caráter científico, pois está subscrito por um nome considerado especialista na questão.

Em contrapartida a essa e às demais perspectivas a-históricas, colocamos uma concepção de letramento como fenômeno que pode atuar indiretamente, influenciando também culturas e pessoas que não dominam a escrita. Esse movimento mostra que o letramento é um processo mais amplo do que a alfabetização, mas que está intimamente relacionado com a existência e influência de um código escrito. Biarnès (1998) declara que a relação do sujeito com a letra acarreta uma transformação no ser de tal forma que perturba a identidade; é uma relação que não se dá de maneira 
igual para todos, por estar ligada à história de cada indivíduo.

Com esses pressupostos, podemos considerar como ágrafos ou iletrados somente os indivíduos que vivem em uma sociedade que não possui nem sofre a influência, mesmo que indireta, de um sistema de escrita.

Dentro dessa concepção, o foco de interesse dá um giro: a questão não se resume mais ao domínio de técnicas, habilidades, nem capacidades de uso da leitura e escrita; ela é muito mais ampla, pois nos lança o desafio de termos de descrever em que consiste o letramento dentro de uma concepção de práticas sociais que se interpenetram e se influenciam, sejam essas práticas orais ou escritas, circulem elas dentro ou fora da escola. É preciso considerar, ainda, o papel da memória (histórica e particular), além da história da constituição dos sentidos na escrita e na oralidade. O enfoque duplo da Análise do Discurso pêcheutiana e da Psicanálise lacaniana é que fornece as ferramentas teóricas e metodológicas para essa tarefa.

Vejamos um pouco dessa memória e dessa história.

Em seu livro Vouloir dire, faire dire (Fazer dizer, querer dizer), Haroche (1992) toma a noção de determinação como a condensação verbal de um processo de longa duração e faz um esboço da história dos efeitos da religião e do direito na gramática e no sujeito. Observa, analisando as quatro etapas do ensino da leitura na Idade Média (Lectio, Quaestio, Disputatio, Determinatio), a mudança do estatuto do sujeito em relação ao saber e à linguagem, assim como a transformação das formas de assujeitamento do indivíduo, primeiro à Religião, depois ao Estado.

Retomemos, junto com Haroche (1992), essa história.

\section{Lectio}

Até o século XII, a pedagogia medieval consiste em ler textos. O exercício essencial é a Lectio. Não se comenta, não se interpreta, não se questiona o texto. A dicção, a recitação e a repetição definem por elas mesmas o que se entende por lectio. Trata-se de um método mnemônico e enclausurante. (HAROCHE, 1992, p. 72).

\section{Quaestio}

A Quaestio surge a partir do século XII. O sujeito torna-se leitor e, como 
preço a pagar pelo privilégio desta leitura, cabe-lhe anular toda a ambiguidade do texto que lê. São imputadas a esse leitor a responsabilidade e a culpa pelas "falhas" (contradições, incoerências) que aparecem nos textos de interpretação da Sagrada Escritura (HAROCHE, 1992, p. 73).

\section{Disputatio}

Na metade do século XIII, ocorre um alargamento da definição restritiva da Quaestio. A Disputatio começa a fazer parte das atribuições das tarefas do mestre na faculdade de teologia. Distanciando-se da leitura entendida no sentido de comentário, de paráfrase estrita, para deslizar, com perguntas em direção ao texto, a Disputatio traz o questionamento de qual a melhor leitura para um determinado texto (HAROCHE, 1992, p. 74).

\section{Determinatio}

Surge em função de a contradição ser impossível no plano doutrinal. Através desse exercício, apesar de haver respostas contraditórias a uma questão, a autoridade estipula uma verdade, e nesta não há espaço para contradições. Cabe ao mestre escolher uma "versão" e colocá-la como verdadeira: "a" interpretação verdadeira, correta (HAROCHE, 1992, p.76).

Diante do exposto, acreditamos ser possível considerar a existência de certo paralelismo entre os exercícios pedagógicos religiosos medievais (que se caracterizam pelo princípio da não contradição e, por isso mesmo, consideram a leitura como recitação) e os exercícios pedagógicos atuais, que, a nosso ver, são marcados pela repetição e pela voz única do professor (ou do livro didático). Trata-se da memória histórica (o interdiscurso) ecoando - e ainda produzindo seus efeitos - na atualidade.

Respeitadas as diferenças, e sem entrar nos detalhes sobre cada uma das formas de exercício, ressaltamos que, tal qual nos exercícios medievais, a prática de ensino no sistema atual baseia-se fundamentalmente em propostas de atividades que induzem o leitor à repetição de textos cujos sentidos são aparentemente transparentes e unívocos. Entendemos que essas atividades não permitem que haja 
espaço para a interpretação, visto que esta é dada anteriormente à leitura. Caso haja discordâncias, é a "autoridade" do livro didático (o texto sagrado moderno), retomado na voz do professor, que vai decidir a interpretação "correta". É o que podemos observar nos recortes abaixo, coletados por Assolini:

Recorte 1

Professor - Apague bem depressa, J., apague tudo isso. Copie lá da lousa a resposta certa. Eu acabei de escrever lá na lousa a resposta certa e você nem olhou. Senta direito e olha pra lá.

Aluno J. - Mas eu acho que o príncipe não devia ter ido casar com a princesa porque ela é uma dragoa mesmo, e ela rasgou, depois comeu a capa dele.

Professor - Mas no texto, no final, ele se casa com a princesa. Copie lá da lousa. (ASSOLINI, 2003)

Recorte 2

A cigarra e a formiga

Interpretação

Sublinhe somente as frases que estão de acordo com o texto:

A cigarra alegrava a vida das formigas.

A formiga não recebeu a cigarra em sua casa.

A cigarra morreu de tanta fome.

A cigarra é uma grande cantora.

Numere as frases na ordem em que os fatos ocorrem no texto. Depois, copie- -os na sequência correta e obtenha um resumo da história.

Então a cigarra foi pedir ajuda à formiga.

A cigarra passou o verão cantando, e as formigas, trabalhando sem parar.

A formiga, amigavelmente, acolheu a cigarra em sua casa até o tempo ficar bom.

$\mathrm{O}$ verão passou, o inverno chegou e a cigarra ficou com frio e com fome, pois não tinha onde se abrigar e o que comer.

Copie da história uma fala da:

cigarra

formiga

(ASSOLINI, 2003).

Os recortes 1 e 2 mostram que há a supremacia da técnica: cópia, reprodução, repetição, desprezo pelo lúdico, etc. No recorte 1 , nota-se que as tentativas feitas 
pelo sujeito-aluno a fim de defender sua posição (suas "ideias") são rechaçadas pelo sujeito-professor, que, através do uso do imperativo, instala um silenciamento e um desequilíbrio no diálogo. Ficam indiciadas também, ali, duas formações discursivas antagônicas: a primeira, monologizante e pretensamente "objetiva", cujo objeto de referência é o livro didático, divinizado e representado como o lugar da verdade; a segunda - que é silenciada - argumentativa e de inclusão do outro no diálogo, que seria caracterizada por índices linguístico-discursivos de inclusão do outro e de emergência da subjetividade. No recorte 2, não se dá espaço algum para que o aluno "entre" e tenha oportunidade de modificar o dito com outras proposições, vindas de outros lugares do interdiscurso. O resultado é que o fosso que separa os alunos de classe baixa da cultura dominante fica mais intransponível, pois não há identificação possível para que ele se sinta aceito e “capaz". Em regra, não existe uma preocupação com o problema de que a falta de leitura dos alunos provenha do fato de que os textos que devem entender muitas vezes não lhes fazem sentido. Ensina Biarnès (1998) que

se a palavra é "para o outro presente", a letra é para o "outro ausente". A letra me permite encontrar o outro, encontrar a alteridade e, sobretudo, construir "meu outro" em mim. A letra, objeto do outro se a leio, objeto para o outro se a escrevo, é um espelho mágico que me permite reconhecer-me, descobrindo-me outro. O problema do acesso à leitura, como o da iniciação à escrita, está aí. Para que, pela letra, eu possa conhecer-me outro, é necessário que eu possa antes reconhecer-me nela. Se sou obrigado a reconhecer nela o outro que eu deveria ser, antes de me reconhecer a mim próprio, encontro-me mergulhado num non-sens, num delírio. É o problema da aprendizagem da leitura (letras do outro) quando não houve antes iniciação à escrita (minhas letras - cartas - para o outro). É o problema da alfabetização numa língua diferente da materna, é o problema dos "métodos" de leitura, sejam quais forem, quando, em vez de serem uma ferramenta a serviço do aprendiz, fazem dele o objeto de uma ideologia pedagógica. Tudo o que o aluno pode fazer é, então, aderir ao espelho oferecido da letra, sem nele se reconhecer. Essa aderência anula todo espaço de jogo e, impedindo então de se ver outro, impede o acesso a qualquer funcionalidade da letra, ou então cria uma funcionalidade mínima que logo se perderá (BIARNÈS, 1998, p. 2 - destaques do autor).

Os discursos altamente letrados - científico, pedagógico, escolar - ao fazerem uso da lógica, alimentam a ilusão de que esta lhes é exclusiva, e a única considerada 
adequada, e também que essa seria a forma predominante na sociedade moderna, por, supostamente, tornar o discurso mais organizado e claro para o sujeito, e sustentar, ao mesmo tempo, a crença de que todos são iguais para usar a língua, o que está de acordo com os ideais de manutenção da "ordem social" e de uma sociedade logicamente estabilizada. É essa a sustentação da proposta de uma "escola para todos".

Em oposição, a concepção histórica de letramento exposta acima pretende discutir as diversas teorizações sobre a escrita passíveis de ser incluídas nesse jogo relacional, opondo-se a concepções que colocam à margem da escola - e de seus conteúdos - a diversidade dos saberes cotidianos presentes nas ricas e variadas manifestações orais da língua e também aquelas produções escritas que não foram legitimadas pelo sistema educacional (como o cordel e o folclore, por exemplo).

\section{Letramento: o outro lado}

As pesquisas de Tfouni (1988, 1992, 2001, 2005, 2006a, 2006b, 2008), Tfouni e Pereira (2009) e Pereira (2002, 2005) e também de Belintane (2008) mostram que a separação entre língua oral e língua escrita é um artifício usado pela escola, numa atitude grafocêntrica. Esse gesto subordina-se a uma ideologia que prega a superioridade da escrita e despreza a importância das práticas discursivas cotidianas (linguageiras, em oposição a metalinguísticas) para o desenvolvimento do letramento.

A perspectiva histórica do letramento questiona o gerenciamento da ciência galileana, que guia as posturas educativas fundamentadas em modelos prescritivistas de alfabetização (baseados em habilidades como uso do espaço gráfico, correspondência som/grafema e coordenação motora), que foram incorporadas ao discurso pedagógico escolar, promovendo a exclusão e o fracasso escolar das crianças e jovens que vivem na pobreza ou abaixo dela. Essa exclusão está fundamentada exatamente na concepção de que na escola deve-se ensinar a pensar de maneira objetiva e a utilizar a variante culta da língua (escrita), que esses alunos não dominam. Segundo Belintane, essa realidade perversa instiga os estudiosos a 
tentar (de)cifrar um incômodo e renitente enigma escolar: por quais motivos alunos oriundos das classes desfavorecidas resistem tanto à entrada na escrita? Por que preferem o duro trabalho braçal, ou mesmo o risco de enfrentar a polícia no tráfico, à atitude silenciosa e pacífica de se debruçar sobre letras? (BELINTANE, 2008, s.p.).

É preciso levar em consideração que aprender a ler e escrever não é tarefa fácil para os membros da classe pobre. Além da exigência de dominar a norma padrão (que não é aquela que usam no cotidiano), há toda a questão da simbolização do código escrito, das regras escolares, das exigências, às vezes absurdas, do discurso pedagógico; enfim, é como se o aprendiz entrasse em outro país, onde se fala outra língua e onde há regras de comportamento diferentes. É como mudar de mundo, nas palavras de Biarnès (1998).

O que ocorre é que, no momento em que a criança pobre entra na escola e precisa dominar a língua escrita, há uma situação de diglossia, que afeta a identidade do sujeito, visto que ele se vê colocado diante de duas línguas, e somente uma delas lhe é plenamente acessível (não é a que proporciona o sucesso: esta é a língua da escola).

O depoimento de Annie Ernaux (1991) no seu romance Les armoires vides ilustra essa sensação de perda da identidade do sujeito da classe baixa diante da língua culta, e também mostra os sobressaltos e medos de quem precisa mudar de código e se adaptar à língua própria daqueles que dominam a escrita:

A professora fala lentamente, com palavras muito compridas, ela não tem nenhuma pressa... Pendurem o agasalho no cabide! Minha mãe berra: não largue o casaco por aí, quem que vai guardá? Tem um mundo separando as duas... Em casa, cabide ninguém sabe o que é; agasalho, não se diz. Pior que uma língua de gringo, se fosse alemão ou turco, a gente já sabe que não vai entender. Mas na escola, eu entendia quase tudo o que a professora dizia, mas sozinha não conseguiria fazer... A língua de verdade, era em casa que eu ouvia; a birita, o rango, ser enrolado, dá uma beijoca, neguinha. As coisas estavam todas lá, na casa, os gritos, as caretas, as garrafas pelo chão. Quando a professora falava, as coisas não existiam! ERNAUX, 1991 apud BIARNĖS, 1998, s. p.). 
No depoimento da escritora, chamamos a atenção para o significante "verdade": "a língua de verdade". Que língua seria essa, e qual seria a outra, que a ela se contrapõe: a língua "de mentira"? A autora diz que a língua de verdade ela ouvia em casa. Ou seja: é a língua em sua forma oral, a língua que serve de suporte para o relacionamento cotidiano, para o diálogo e a disputa entre gerações, troca de experiências e visões do mundo. É aquela que identifica e aproxima os semelhantes, ou os distancia acatando uma alteridade. Feita muitas vezes somente de retalhos esgarçados, repetições, hesitações, esse discurso carrega particularidades do sujeito, de sua memória particular e de seu contexto sócio-histórico.

No discurso oral produzido por sujeitos pouco escolarizados e de classe baixa, o saber não aparece na forma de definições, explicações e metalinguagem, como se mostra na escrita. A descrição de estereótipos, ou a busca de "receitas" prontas quanto a um método "certo" de ensinar a ler e escrever, cremos, afeta a identidade do sujeito. O discurso escolar, influenciado pela escrita, faz uso da metalinguagem (como é o caso das definições e equivalências) e constitui-se em um tipo de discurso que exige do sujeito que se coloque numa posição em que suas experiências e conhecimento factual podem ser dispensados e negados. O esforço que os alunos de classe baixa fazem para conseguir acompanhar a língua falada da escola e, ainda por cima, para aprender a representá-la por escrito, frequentemente passa despercebido dos agentes educacionais, os quais, aprisionados às normas do bemfalar e do bem-escrever, muitas vezes ficam insensíveis à riqueza e à criatividade de algumas escritas. Somente como ilustração, apresentamos o texto abaixo, coletado por Assolini para seu doutoramento.

Era uma vez um patinho, um principi e uma princeza. Eles brincarão no parqui perto do supermercadu foi lá que o principi falou pra princeza vou sauvar você da dragoa feros vou sauvar você de todos os jacares ela e ele viverão felizes pra sempre. O principi foi ser cindico do prédio grandão e a princeza começou a costurar pra fora pra ganhar uns trocadinho. (ASSOLINI, 2013).

O texto apresenta algumas características que ilustram a interpenetração de oralidade e escrita. Nota-se, por exemplo, a grafia fonética de certas palavras, como "principi”, "supermercadu", "sauvar", etc. Tais trocas não devem ser consideradas 
erros; são, antes, hipóteses a respeito de como se devem escrever palavras que até então só circulavam para o sujeito na forma oral. Por outro lado, é de notar a habilidade que o sujeito mostra para estruturar uma narrativa, com seus principais elementos: personagens, lugar, enredo, temporalidade, conflito, resolução e coda. É muito interessante o uso que o sujeito faz do arquivo, ou campo dos documentos que constituem sua memória discursiva, ao compor a ação da narrativa: por exemplo, brincar no parque perto do supermercado, ao lado do conhecimento sobre os feitos heroicos que o personagem masculino deve praticar principalmente nos contos de fada e nas narrativas de cavalaria (salvar a princesa da "dragoa" feroz). A condição de classe social pobre aparece também, através da submissão à ideologia dominante: mesmo sendo príncipe, ele foi ser síndico de um prédio, e mesmo sendo princesa, ela foi costurar para fora a fim de ganhar um dinheirinho, o que indicia a ideologia referente ao papel secundário da mulher para o sujeito-narrador. $\mathrm{O}$ sujeito consegue estabelecer um diálogo entre posições conflitantes, e resolve uma aparente contradição. Ao fazer isso, atinge um efeito de humor, que provoca o riso do leitor.

Essas colocações implicam admitir a hipótese de que o sujeito do discurso não é uno e previsível como pretende o discurso pedagógico, mas é um sujeito dividido, submetido à incompletude da linguagem. A figura topológica da banda de Möbius, tal como proposta por Lacan (2006), ilustra a continuidade e a interpenetração entre práticas orais e práticas escritas da língua, como defende a perspectiva histórica do letramento.

Vejamos uma ilustração da banda:

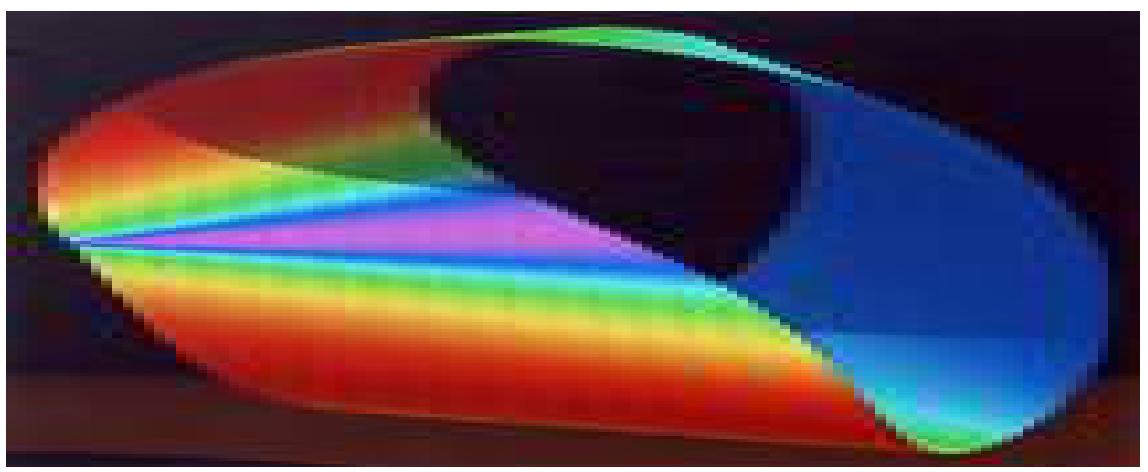

Figura 1 - Banda de Möbius - Fonte: LARANJEIRAS, 2012, s. p. 
Se caminharmos ao longo da banda, veremos que não há avesso nem direito; não há dentro nem fora. A dicotomia oral/escrito, representada pela famosa metáfora da folha de papel, ou da moeda, não serve mais neste caso. O sujeito, nesse percurso pela banda, pode oscilar entre oralidade e escrita. Pode, por exemplo, falar como se escrevesse, ou escrever como se estivesse conversando.

Diz Lygia Clark (1983, p. 151): "uma fita de Moebius quebra os nossos hábitos espaciais: direita-esquerda, anverso e reverso, etc. Ela nos faz viver a experiência de um tempo sem limite e de um espaço contínuo". Tal como a moeda, ou a folha de papel, que só oferecem dois lados, o discurso pedagógico apresenta o "certo" e o "errado" na maneira de escrever. A banda de Möbius, por sua vez, oferece infinitas possibilidades no discurso que envolve a relação entre oralidade e escrita, inclusive no espaço escolar.

\section{O processo histórico do letramento e a resistência do sujeito}

Diante do que expusemos até aqui, queremos sinalizar que existe uma saída para o sujeito, um escape das malhas do discurso pedagógico logicizante que tenta interpelá-lo todo o tempo. Esse gesto implica levar conta de que maneira a diversidade de manobras interpretativas pode romper com uma "economia escriturística" (CERTEAU, 2001) pela qual se elencam formas supostamente mais aprimoradas de gestos de leitura (TFOUNI; PEREIRA, 2009).

Para Certeau, o escriturístico é o que se aparta do mundo das vozes e da tradição e encaminha para um ato automático ordenado do dizer, tal que não haja tempo e espaço "perdido" para muitas explicações ou reviravoltas interpretativas. Assim, a economia escriturística é a produção de um padrão de leitura linear por meio de um texto social geral calcado em leis abstratas. Essas leis eliminaram a composição coletiva e grupal de um texto em favor do formato individual, que se manifesta pelas vozes autoritárias do Estado, da escola, da ciência. Estas servem, segundo o autor, para dar estabilidade aos discursos e fazê-los se adequarem à lógica da leitura e da escritura que a razão técnica impôs aos modos cotidianos do saber.

Como se dá, na prática, a prevalência do processo de letramento sobre a economia escriturística do discurso pedagógico? Vimos que a escola - e, consequentemente, a educação, e as práticas discursivas que circulam nesse espaço institucional - instalam 
um domínio de memória percorrido por formações discursivas que se prestam a definir não só o que é verdadeiro, como também a determinar as formas linguístico-discursivas que irão veicular essas "verdades". ${ }^{1}$

Existe uma aparente boa intenção nessa normatização das formas linguístico-discursivas que são objeto do discurso pedagógico: trata-se do intuito de igualar a todos ("escola para todos") com relação aos diferentes usos da língua, fundamentado no postulado de uma comunicação sem erros, sem equívocos, concorde a um ideal de clareza e bem-dizer, e também numa formação ideológica, segundo a qual o discurso da ciência, além de ser supostamente neutro e objetivo, representa a "verdade".

Como decorrência desse estado de coisas, a escola coloca um ideal de língua correta, que, aliado à questão da metalinguagem, define todo o funcionamento dessa instituição: o que é "ensinar"; o que é "aprender"; como deve ser o "bom aluno" e o "mau aluno"; quais conteúdos são relevantes, etc.

Em lugar da previsibilidade sobre as qualidades de bom ou mau aluno, a proposta histórica aqui defendida considera todos os alunos como tendo certo grau de letramento, bem como um arquivo, constituído tanto por textos orais quanto escritos (mesmo não tendo tido contato direto com estes, visto que a influência da escrita na sociedade moderna se faz muitas vezes de maneira indireta). Isso se deve em grande parte à influência da mídia em suas várias modalidades.

Para ampliar o alcance do que dizemos aqui, retomaremos, neste ponto, análise desenvolvida por Tfouni, Toneto e Adorni (2011) sobre um texto de aluno de $8^{\text {a }}$ série (hoje 9aano), de escola da rede pública de Ribeirão Preto, desenvolvido em consonância com as propostas do Saresp (Sistema de Avaliação e Rendimento das Escolas de São Paulo). ${ }^{2}$

A tarefa proposta partia da citação de um trecho do livro "Cem dias entre céu e mar", de Amyr Klink, cujo cerne era a descrição de um sonho. A proposta de exercício era apresentada a seguir:

Certamente, você já teve sonhos tão emocionantes como esse, relatado por Amyr Klink. Escreva uma história narrando aventuras vividas em um sonho, em que você e seus amigos são os personagens principais.

1 Consideramos, aqui, fundamentalmente, os discursos que circulam na rede pública de ensino.

2 Esse recorte foi retirado do corpus da pesquisa de mestrado de Adorni (2010). Uma discussão detalhada da redação do aluno foi feita em Tfouni, Toneto, e Adorni (2011). 
Não se esqueça de dar um TíTULO a sua história. (SARESP, 2005 apud ADORNI, 2010).

Diante dessa proposta, um dos alunos produziu o texto que reproduzimos a seguir. Sua escrita deu-se a partir da mobilização da parte do arquivo à qual o aluno tem acesso, expressando-se pela interpenetração das formas orais e escritas da língua.

Nas observações que se seguem, inspiradas pela discussão feita por Tfouni, Toneto, Adorni (2011), pretendemos contrapor os critérios do discurso pedagógico, que dão ao texto do aluno uma avaliação ruim, aos critérios sócio-históricos do discurso desse sujeito, valorizados pelo processo histórico do letramento.

\author{
O TIRO (J. C.) \\ EU SONHEI QUE \\ O DULE E O FABRICIO \\ O CHRISTOPHER LEVOU \\ UM TIRO QUANDO ERA \\ PEQUENO. AI NOIS FOI PARA \\ O MEDICO FICAMOS \\ 2 ANOS EM COMA DEPOIS \\ NOIS MORREMOS E FOMOS \\ NO MUNDO DO TEIETOBIES \\ E AI NOIS TRONBO O \\ BOB ESPONJA AS MENINAS \\ SUPER PODEROZA MEU PRIMO \\ JOÃO GRILO CABRA DA PESTE. \\ ADIVINHA QUEM QUE EU VI \\ LÁ QUEM, QUEM, O RONALLLLLDO. \\ ERA BOM SE FOSSE MAIS ERA \\ TUDO UM SONHO. \\ FIM
}

À primeira vista, o aluno não escreve uma narrativa de sonho conforme os moldes propostos pelo discurso pedagógico. Segundo essa perspectiva, o sujeito que emerge nesse discurso é "apagado" e não tem valor dentro do discurso monologizante e autoritário da escola; as propostas de produção de texto estabelecidas na prova do Saresp "passam a noção de que entendem a produção textual do aluno como "produto' e não como resultado de um processo de interação" 
do aluno com as condições de produção de seu texto (DORTA, 2007, p. 136).

Já sob a perspectiva histórica do letramento, podemos observar que o aluno conta uma história começando com a frase "eu sonhei" e terminando com "era tudo um sonho", conforme solicitado. A descrição de acontecimentos confusos retrata o modo de ser dos sonhos, mesclando fatos cotidianos com ficção, tal como a do encontro com o jogador Ronaldo, ídolo da torcida brasileira.

Como apontado em Tfouni, Toneto e Adorni (2011), de saída, a leitura do texto mostra que o aluno, em certa medida, e dispondo de seus recursos (o arquivo, acima mencionado) estrutura o seu texto em forma de poema, com rimas e estrofação, construindo versos, paronomásias ("fomos", "morremos", "primo"; "que, quando, ficamos", "coma"), além de estrutura rítmica, ditada por versos que variam entre 6 a 8 sílabas métricas, e cujos acentos evocam a sonoridade do rap. ${ }^{3}$

Podemos observar que o texto não é de todo inadequado à proposta, pois não se trata de uma escrita em que o aluno coloca quaisquer dados. Há coerência discursiva estrutural - que preenche o desafio inicial colocado - na qual emerge o "poeta interior" do sujeito, lugar discursivo em que ele fala de seus desejos, de seus amigos, enfim, da realidade em que vive, dando oportunidade para a emergência de multiplicidade de sentidos. Embora a narrativa do aluno não se estruture em prosa - o que, diga-se de passagem, não é solicitado na proposta - é possível descobrir ali uma narrativa com começo, meio e fim, sequenciados; há um desequilíbrio - provocado pelo tiro - que leva os personagens ao clímax dessa narrativa peculiar - a morte -, viabilizando seu acesso ao mundo da ficção. A "descoberta" de que tudo não passa de um sonho encerra com chave de ouro esse texto dotado de dicção narrativa e da ambiguidade intrínseca ao mundo onírico: "era bom se fosse, mas" ou, sem a correção ortográfica e sintática: "era bom se fosse mais".

Por mais que o discurso pedagógico esteja ancorado em uma perspectiva higienista e monológica da língua (TFOUNI, 1992, 2006b), nosso ponto de vista, retomando a metáfora da moeda, que mencionamos acima, que prescreve uma maneira "certa" e uma "errada" de escrever, ao contrário, é que a estrutura discursiva, o modo como o discurso do sujeito funciona é estruturado como a

3 A sigla RAP é formada a partir das iniciais de rhythm and poetry - ritmo e poesia, em inglês. Rap é um tipo de discurso rítmico com rimas. 
banda de Möbius: não há só duas opções, dois sentidos, mas há sentidos múltiplos. Por mais que a ideologia pedagogizante tente conformar as práticas discursivas a uma verdade, há algo que perturba esse processo e faz emergir novos sentidos. Como apontam Tfouni:

Se pensarmos que a brincadeira e a escrita criativa, enquanto veículos da fantasia, permitem a realização do desejo (FREUD, 1975 apud CARREIRA, 2009, p. 21), podemos dizer que estas conseguem corrigir uma realidade insatisfatória, fantasmática. No caso do texto criativo do aluno, essa correção permite a revelação de algo que deveria ficar silenciado, mas que escapa, no discurso, como função poética; escape este que é carregado de estilo, da marca que ele imprime, com sua escrita (LACAN, 1966), na página em branco à sua frente, de modo que, avançando nessa ideia, ainda com Carreira (2009, p. 23), podemos afirmar que: "o estilo é o que se decanta do acontecimento que (re)produz a fantasia do sujeito", o seu canto, a sua voz. A fantasia é, pois, a orquestra do sensível a recobrir o inteligível; e a escuta do sensível é que deveria servir de mote ao professor para a realização do seu trabalho (TFOUNI; TONETO; ADORNI, 2011, p. 439).

A riqueza da construção poética do texto configura-se, nessa escrita, como o lugar por excelência onde fica indiciado o grau de letramento do sujeito. Há um letramento poético em jogo, dado pela interpenetração das práticas orais e escritas da língua, que deriva de um saber do aluno, embora, claro, a sua consciência sobre seu domínio do poético não lhe seja tão evidente. Se o professor tomar o texto do aluno como produto de seu letramento, e não como marca de seu "analfabetismo funcional", poderá angariar caminhos para indicar-lhe como aprimorá-lo, pois, sem a leitura do professor, o texto e suas potencialidades poéticas e narrativas não se realizam. Se o professor perceber os jogos poéticos na redação do aluno como resultado do seu grau de letramento, marcado pela sua realidade sócio-histórica, e não da sua incapacidade; se aceitar que seu aluno pode, e deve, ocupar diferentes lugares de interpretação (pois o papel da escola é justamente indicar isso aos alunos), então teremos um sujeito agente, que será capaz de contribuir na construção do processo autoral da redação, processo esse que, graças ao arquivo que o aluno aciona, é singularmente poético e criativo. Desse modo, o professor será capaz de levar seu estudante a estabelecer reflexões linguístico-textuais 
sobre a norma, sobre o léxico e também sobre o discurso (TFOUNI; TONETO; ADORNI, 2011, p. 440).

Não pretendemos negar que há dificuldades evidentes na escrita do aluno, mas rejeitamos que elas sejam marcas de "fracasso" e de dificuldade. Nossa proposta, seguindo a teoria histórica do letramento, é o resgate do sujeito que se inicia na escrita. Se esta for tomada como um espelho mágico que permite que ele se (re)conheça, descobrindo-se outro (BIARNÈS, 1998), não podemos enxergar o produto de sua escrita como um nonsens segundo os métodos de leitura preconizados. Buscamos repensar a escrita sob a funcionalidade de um espelho, em que o sujeito possa se reconhecer, falar de si, de sua realidade, e não como algo estranho a ele, ininteligível, que fale de um outro mundo, de uma realidade que não é a dele. Sob essa perspectiva, podemos compreender por que Tfouni (1992) relaciona o letramento a um continuum, mostrando que, do ponto de vista desse texto, o sujeito não pode ser classificado como iletrado, nem pouco letrado.

A fim de demonstrar que o aluno foi coerente à proposta de redação que lhe foi colocada, retomemos alguns dos aspectos de seu texto realçados por Tfouni, Toneto, Adorni (2011) para enfatizar nossas considerações. Ao utilizar o operador "Eu sonhei" logo no início do texto, traça um caminho que irá direcionar a escolha e o deslocamento de significantes, sintagmática e paradigmaticamente e, consequentemente, o sentido do texto. Como pontuam as autoras, sem esse recurso argumentativo o texto seria marcado pela dispersão, podendo ser avaliado pelo leitor como um texto esgarçado, pouco coeso e sem coerência. Entretanto, o operador "Eu sonhei", do início do texto, garante a verossimilhança, pois nos sonhos é possível que os personagens de ficção coadunem-se à realidade do sonhador.

Por outro lado, ainda como apontam Tfouni, Toneto e Adorni:

do ponto de vista psíquico (referente à emergência da verdade do sujeito) é notável que esses dois mundos (ficção, realidade) são entrelaçados ao redor do significante "morte", que é o balizador de toda a cadeia, o que lhe dá o estatuto de significante-mestre. O encontro entre o balizador sintático ("Eu sonhei") e o balizador do desejo ("nois morremos") propicia ao sujeito que fale de coisas impossíveis na realidade, atribuindo-lhes um caráter de verossimilhança. Esta característica de verossimilhança 
revela um especial investimento do sujeito quando faz uso da intertextualidade, no trecho: "Meu primo João Grilo Cabra da Peste". Esse movimento de introdução de uma personagem da obra: O Auto da Compadecida (de Ariano Suassuna), João Grilo, que é apresentado como primo, fortalece a interpretação de que, tanto no sonho quanto na morte, tudo pode acontecer (são fenômenos que fogem ao controle do sujeito). (TFOUNI; TONETO; ADORNI, 2001, P. 447 - destaques do autor).

Conforme afirma Tfouni (1992, 2006a, 2006b), há discursos alternativos ao discurso formalizado da escola. Essas alternativas, baseadas no conhecimento cotidiano, na experiência pessoal e nas histórias particulares de leitura, fazem suplência à ausência de conhecimento formal sobre as regras do "bem-escrever" e ao baixo grau de letramento e escolaridade.

$\mathrm{O}$ que o processo histórico do letramento propõe é que o problema dos métodos de leitura reside no fato do apagamento do sujeito do discurso em prol da manutenção da ordem social. O que tentamos mostrar é que esse objetivo de manutenção da ordem social, de igualdade no programa "escola para todos" é um sistema perverso, pois se baseia na ilusão de que existe comunicação total, de que se pode dizer tudo, de que existe "a" verdade. O paradoxo que esse sistema esconde é o de que essa homogeneização acentua a desigualdade, marginaliza aqueles que a ele não aderem, anulando o espaço de jogo, a funcionalidade da letra em que o sujeito pode se reconhecer.

Propomos que os educadores, em suas práticas, favoreçam a emergência da autoria de seus alunos, desconfiando da veracidade do genérico discursivo escola para todos, que, em vez de trazer a ideia de inclusão social, concebem os textos dos alunos a partir de uma visada monolítica, concebem os problemas da escola como problemas dos alunos. Desse modo será impossível assegurar minimamente uma escola adequada para a maioria. Levar em consideração, ainda, a história da produção de sentidos e as práticas sociais que os concretizam e atualizam uma memória historicamente constituída é relevante para considerar nas práticas de letramento as condições de classe, a singularidade (e as diferenças), além do respeito à polifonia que precisa ter um lugar na sala de aula.

A “escola para todos" é um genérico concebido sob o paradoxo de, ao mesmo tempo, ser todo inclusivo e marginalizar aqueles cujas letras não aderem ao discurso 
dominante, por trazerem para sua escrita valor particular e não universal (como preconiza a ideologia pedagogizante), quando trazem "um barulho inquietante de uma outra tradição" (CERTEAU, 1994, p. 249). Nas palavras de Vernant, esse processo é possível porque:

Em lugar de morrer sua bela morte, o mito sobrevive dentro daquilo a que nomeamos ideologia [...] O mito, com efeito, não conhece outra ordem de prioridade além de uma força cega, a força pulsional, que homogeneíza todos os objetos em seu trajeto, que tende a submergir o real em seu percurso. Nenhuma urgência se equipara à vontade todo-poderosa, à vontade de poder, à qual o mito obedece. Além disso, se essa vontade perde sua aresta de corte, o mito simplesmente morre, deixando a descoberto a questão que ele encobre: a questão do sujeito (VERNANT, 1982 apud PÉCAUT, 1982, p. 11, tradução nossa).

Pensar, portanto, o letramento e a verdade do sujeito em convergência, pode conduzir os educadores a um exercício ímpar de escuta, não do que eles querem ouvir, mas daquilo que seus alunos, a partir de seus arquivos, de sua inserção socioistórica, podem dizer/escrever.

\title{
The historic approach of literacy: echoes of memory in the current times
}

\begin{abstract}
The word literacy acquired a polysemy spectrum which put it away from the notion of social and historic process, at the same time that associates it to codification and decodification of writing. Concerning to this last perspective, we would have nothing to add. However, we sustain, in this paper, considering Pêcheux's Discourse Analysis and Lacanian Psychoanalysis approaches, that there is a conception of literacy as a phenomenon which influences indirectly individuals and cultures for whom the competence of writing is not established. In this sense, the concept of literacy is larger than alphabetization. As an evidence of this proposal, we analyze a text written by a student, that demanded him to write about a
\end{abstract}


context distant from his own, and, to do so, he mobilized places from the archive and from his particular memory, showing a singular knowledge of writing culture, even though his text presents interpenetration of oral an writing forms, aspect that is not allowed by those who defend an a-historical conception of literacy. We discuss that the student's text ran away from the reduction of a merely pedagogic ideology and reflects a discursive coherence in face of the challenge that was proposed to him. By the end of this paper, we propose that the teachers should search for devices that make easier for their students to write texts in which their authorship could emerge.

Keywords: Literacy. Discourse analysis. Ideology.

\title{
L'abordage historique de la littéracie: echos de la memoire dans l'actualité
}

\begin{abstract}
Résumé
Le mot littéracie a acquis une polysémie qui l'éloigne de la notion de processus socio-historique et l'associe à la codification-décodification de l'écriture. Sous cette conception, on n'aurait rien à ajouter. On défend dans cet article, sous la perspective de l'analyse du discours pêcheutienne et de la psychanalyse lacanienne, la conception de littéracie en tant que phénomène qu'influencie directement les cultures et les individus qui ne dominent pas l'écriture, parce qu'il s'agit d'un processus plus ample que l'alphabétisation. En tant que support à cette proposition, on analyse le texte d'un élève qui, poussé à écrire sur un sujet éloigné de sa propre réalité, mobilise des lieux d'archives et de sa propre mémoire, ce qui indique une connaissance de la culture écrite, même si son produit montre l'interprétation de formes orales et écrites de la langue, fait qui n'est pas accepté par ceux qui défendent une conception a-historique de la littéracie. On discute que son écriture échappe aux mailles réductrices d'une idéologie pédagogisante et reflet une cohérence discursive structurelle au défie qu'on lui a posé. On propose, enfin, que les éducateurs favorisent dans leurs pratiques la poussée de l'expression propre de leurs élèves.
\end{abstract}

Mots-clés : Littératie. Analyse du discours. Idéologie. 
Referências

ADORNI, Alessandra. Ciclo escolar e letramento: uma análise discursiva. 2010. 105 f. Dissertação (Mestrado em Ciências) - Faculdade de Filosofia, Ciências e Letras, Universidade de São Paulo, Ribeirão Preto, 2010.

ANDERSON, Alonzo B.; STOKES, Shelley J. Social and institutional influences in the development and practice of literacy. In: GOELMAN, Hillel; OBERG, Antoinette; SMITH, Frank (Ed.). Awakening to literacy. London: Heineman Educational Books, 1984. p. 24-37.

ASSOLINI, Filomena Elaine Paiva. Interpretação e letramento: os pilares de sustentação da autoria. 2003. 269 f. Tese (Doutorado em Psicologia) - Faculdade de Filosofia, Ciências e Letras, Universidade de São Paulo, Ribeirão Preto, 2003. BELINTANE, Claudemir. Vozes da escrita - em tempos de crianças e menestréis. Estilos da clínica. São Paulo, v. 13, n. 25, p. 36-51, dez. 2008. Disponível em: $\quad<$ http://www.revistasusp.sibi.usp.br/scielo.php?pid=S141571282008000200003\&script=sci_arttext $>$. Acesso em: 24 jul. 2012.

BIARNÈS, Jean. O ser e as letras: da voz à letra, um caminho que construímos todos. Revista da Faculdade de Educação - USP. São Paulo, v. 24, n. 2, p. 137161, jul./dez. 1998. Disponível em: <http://www.scielo.br/scielo.php?script=sci arttext\&pid=S0102-25551998000200009>. Acesso em: 24 jul. 2012.

CARREIRA, Alessandra Fernandes. Autoria e fantasia: cons(c)ertando a realidade insatisfatória. In: TFOUNI, Leda Verdiani (Org.). Múltiplas faces da autoria. Ijuí: Editora da Unijuí, 2009. p. 11-26.

CERTEAU, Michel de. Ler: uma operação de caça. In: CERTEAU, Michel de. A invenção do cotidiano: 1 . Artes de fazer. 6. ed. Petrópolis: Vozes, 2001. p. 259273.

CLARK, Lygia. Livro-obra. In: CLARK, Lygia. O mundo de Lygia Clark. Biografia, 1983. Disponível em: $<$ http://www.lygiaclark.org.br/biografiaPT.asp $>$. Acesso em: 26 jul. 2012.

DORTA, Roseli Aparecida Franco. A produção textual de alunos de $4^{\mathrm{a}}$ e $8^{\mathrm{a}}$ séries do Ensino Fundamental no SARESP: - Sistema de Avaliação de Rendimento Escolar do Estado de São Paulo. Dissertação (Mestrado em Educação) Universidade São Francisco, Itatiba, 2007. Disponível em: $<\underline{\text { http: } / / \text { www.usf.edu. }}$ 
br/itatiba/mestrado/educacao/uploadAddress/Dissertacao_Roseli_Aparecida Franco_Dorta[1557].pdf>. Acesso em: 24 jul. 2012.

ERNAUX, Annie. Les armoires vides. Paris: Gallimard, "Folio", 1991.

FREUD, Sigmund. Escritores criativos e devaneio. In: STRACHEY, James (Org.). Edição Standard Brasileira das Obras psicológicas completas de sigmund Freud. Rio de Janeiro: Imago, 1975. v. 9, p. 149-161. Original publicado em 1908. HAROCHE, Claudine. Fazer dizer, querer dizer. São Paulo: Hucitec, 1992. HIRSCH JR., Eric Donald. Cultural literacy. Boston: Houghton Mifflin, 1987. JACOB, Evelyn, Learning literacy through play: Puerto-Rican Kindergarten children. In: GOELMAN, Hillel; OBERG, Antoinette; SMITH, Frank (Ed.). Awakening to literacy. London: Heineman Educational Books, 1984. p. 73-83.

KLINK, Amyr. Cem dias entre o céu e o mar. São Paulo: Companhia das Letras, 2003.

LACAN, Jacques. Lição de 2 de dezembro de 1964. In: Problemas cruciais para a psicanálise. Centro de Estudos Freudianos do Recife, 2006. Original publicado em 1964.

LACAN, Jacques. Abertura desta coletânea. In: LACAN, Jacques. Escritos. Rio de Janeiro: Jorge Zahar, 1966. p. 9-11.

LANGER, Judith A. A socio-cognitive perspective on literacy. In: LANGER, Judith A. (Ed.). Language, literacy and culture: Issues of society and schooling. New Jersey: Ablex Publishing Corp., 1987. p. 1-20.

LARANJEIRAS, Cássio C. A fita de Listing-Möbius: a matemática da beleza e do mistério. In: Experimentum. Um espaço dedicado à reflexão e ao diálogo. Disponível em: $\quad<$ http://www.experimentum.org/blog/?tag=fita-de-mobius $>$. Acesso em: 26 jul. 2012.

OLSON, David R. See! Jumping! Some oral antecedents of literacy. In: GOELMAN, Hillel; OBERG, Antoinette; SMITH, Frank (Ed.). Awakening to literacy. London: Heineman Educational Books, 1984. p. 185-192.

PEREIRA, Anderson de Carvalho. Letramento, heterogeneidade e alteridade: análise de narrativas orais produzidas por uma mulher não-alfabetizada. Monografia (Bacharelado em Psicologia) - Faculdade de Filosofia, Ciências e Letras de Ribeirão Preto, Universidade de São Paulo, 2002.

PEREIRA, Anderson de Carvalho. Letramento, esquecimento e alteridade: o processo de reificação da escrita. Dissertação (Mestrado em Psicologia) - 
Faculdade de Filosofia, Ciências e Letras de Ribeirão Preto, Universidade de São Paulo, 2005.

SARESP. Disponível em: <http://saresp.fde.sp.gov.br/2005/index.htm>. Acesso em: 12 jan. 2013.

SOARES, Magda. Letramento e escolarização. In: RIBEIRO, Vera Masagão (Org.). Letramento no Brasil. São Paulo: Global, 2003. p. 89-115.

STREET, Brian, Literacy in theory and practice. Cambridge: Cambridge University Press, 1989.

TFOUNI, Leda Verdiani. Adultos não-alfabetizados: o avesso do avesso. Campinas: Pontes, 1988.

TFOUNI, Leda Verdiani. Letramento e analfabetismo. Tese de Livre Docência n/p. Faculdade de Filosofia, Ciências e Letras de Ribeirão Preto, Universidade de São Paulo, 1992.

TFOUNI, Leda Verdiani. A dispersão e a deriva na constituição da autoria e suas implicações para uma teoria do letramento. In: SIGNORINI, Inês (Org.). Investigando a relação oral/escrito e as teorias do letramento. Campinas, SP: Mercado de Letras, 2001. p. 77-97. (Coleção Ideias sobre linguagem).

TFOUNI, Leda Verdiani. Letramento e autoria: uma proposta para contornar a dicotomia oral/escrito. Revista da ANPOLL, Campinas, n. 18, p. 127-141, 2005. TFOUNI, Leda Verdiani. Adultos não-alfabetizados em uma sociedade letrada. São Paulo: Cortez, 2006a.

TFOUNI, Leda Verdiani. Letramento e alfabetização. 8. ed. Campinas: Cortez, 2006b.

TFOUNI, Leda Verdiani. Letramento e contenção da deriva. In: TFOUNI, Leda Verdiani (Org.). Múltiplas faces da autoria: análise do discurso, psicanálise, literatura. Modernidade e enunciação. Ijuí, RS: Editora da Unijuí, 2008. p. 141158.

TFOUNI, Leda Verdiani; PEREIRA, Anderson de Carvalho. Letramento e formas de resistência à economia escriturística. Fórum linguístico, Florianópolis, v. 6, n. 2, p. 67-79, jul./dez. 2009.

TFOUNI, Leda Verdiani; PEREIRA, Anderson de Carvalho, Letramento, heterogeneidade e alteridade: análise de narrativas orais produzidas por uma mulher não-alfabetizada. Alfa, São José do Rio Preto, v. 49, n. 1, p. 31-49, 2005. 
TFOUNI, Leda Verdiani; TONETO, Diana Junkes Martha; ADORNI, Alessandra. A dimensão político-pedagógica da 'comunicação sem equívocos' frente aos desafios da escola para todos: novos lugares interpretativos para a prática docente. Linguagem e ensino, Pelotas, v. 14, n. 2, p. 427-453, jul./dez. 2011.

VERNANT, Jean-Pierre. Avant-propos. In: PÉCAUT, Myriam. La matrice du mythe. Essai sur l'inconscient originaire, Paris: Éd. Aubier Montaigne, 1982. 